Faculdade

de Ciências Econômicas UFRGS

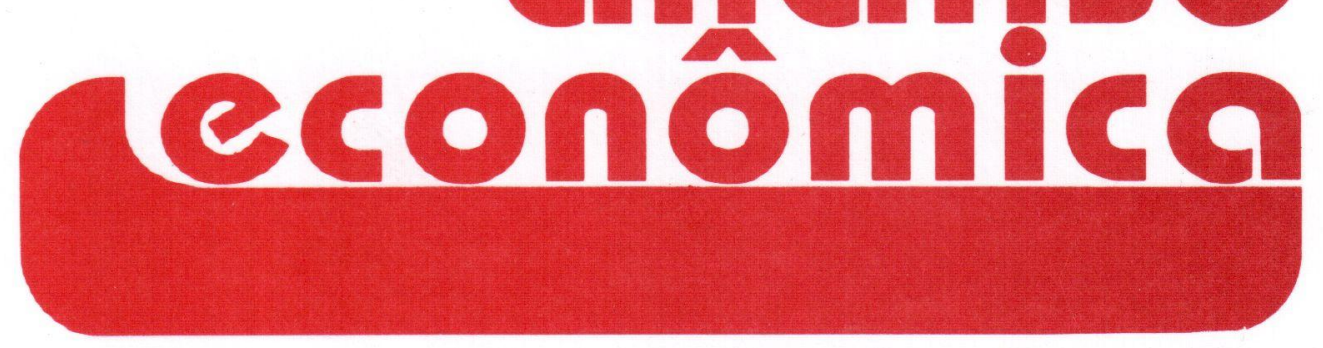

- A INTERNACIONALIzAÇÃo do Sistema FIINANCEIRO: 1990-1992

Lauro Lobo Burle

- GOVERNMENT INTERVENTION, INSTITUTIONAL FACTORS AND MARKET : AN ANALYSIS OF THE WAGE BARGAINING IN BRAZIL

Francisco Galrão Carneiro

- AINSTITUCIONALIZAÇÃO DA PREFERÊNCIA PELA LIQUIDEZ Albério Neves Filho

- PADRÕES MONETÁRIOS ALTERNATIVOS Fernando Carlos G. de Cerqueira Lima

- as contas nacionais e os custos AMBIENTAIS DA ATIVIDADE ECONÓMICA Charles C. Mueller

- LIVROS RECEBIDOS

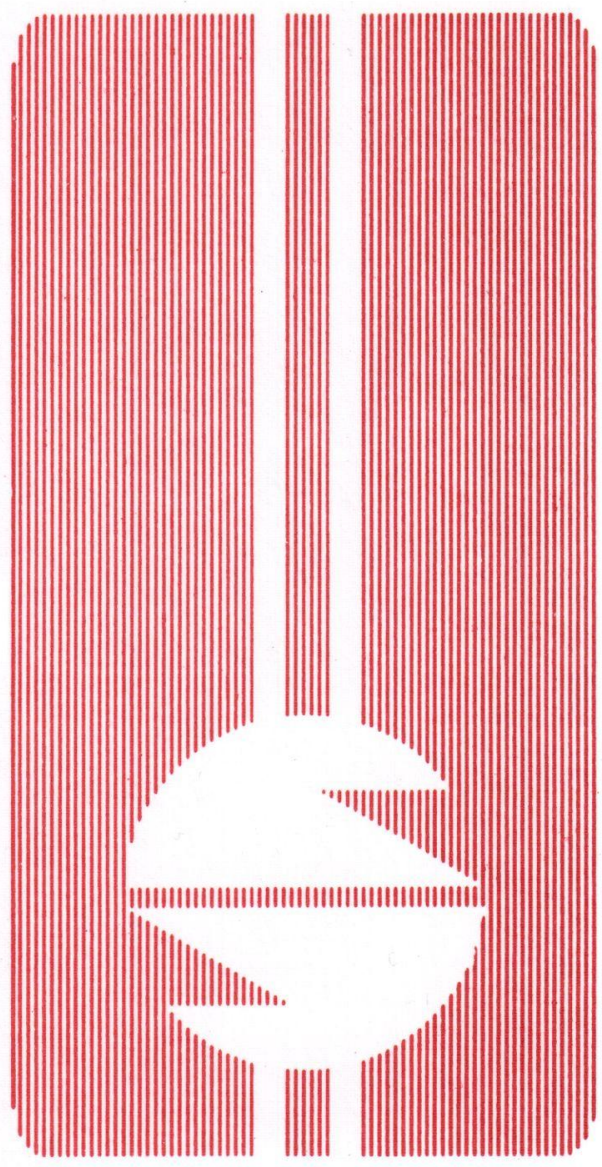


UNIVERSIDADE FEDERAL DO RIO GRANDE DO SUL Reitor Prof. Hélgio Henrique Casses Trindade

FACULDADE DE CIÊNCIAS ECONÔMICAS Diretor. Prof. Pedro Cézar Dutra Fonseca

CENTRO DE ESTUDOS E PEQUISAS ECONÔMICAS

Diretor. Prof. Paulo Alexandre Spohr

DEPARTAMENTO DE CIÉNCIAS ECONÔMICAS

Chefe: Prof. Achyles Barcelos da Costa

CURSO DE PÓS-GRADUAÇÃO EM ECONOMIA

Coordenador. Prof. Roberto Camps Moraes

CURSO DE PÓS-GRADUAÇĀO EM ECONOMIA RURAL

Coordenador. Prof. Atos Freitas Grawunder

CONSELHO EDITORIAL: Achyles Barcelos da Costa, Aray Miguel Feldens, Atos Freitas Grawunder, Carlos Augusto Crusius, Eugênio Lagemann, Fernando Ferrari Filho, Gentil Corazza, Juvir Luiz Mattuella, Marcelo Savino Portugal, Maria Imilda da Costa e Silva, Nali de Jesus de Souza, Nuno R. L. de Figueiredo Pinto, Otília Beatriz K. Carrion, Paulo Alexandre Spohr, Pedro Cezar Dutra Fonseca, Roberto Camps Moraes, Valter José Stülp, David Garlow (Wharton Econometrics Forecasts Association, E. U.A.), Edgar Augusto Lanzer (UFSC), Eleutério F. S Prado (USP), Fernando de Holanda Barbosa (FGV/RJ), Gustavo Franco (PUC/RJ), João Rogério Sanson (UFSC), Joaquim Pinto de Andrade (UnB), Juan H Moldau (USP), Werner Baer (Univ. de lllinois, E. U.A.).

COMISSÃO EDITORIAL: Atos Freitas Grawunder, Pedro Cezar Dutra Fonseca, Marcelo Savino Portugal, Roberto Camps Moraes.

EDITOR: Nali de Jesus de Souza

SECRETARIA: Cláudia Porto Silveira, Jeferson Luis Bittencourt e Vanete Ricachescki (revisão de textos).

FUNDADOR: Prof. Antônio Carlos Santos Rosa

Os materiais publicados na revista Análise Econômica são da exclusiva responsabilidade dos autores É permitida a reprodução total ou parcial dos trabalhos, desde que seja citada a fonte.

Aceita-se permuta com revistas congêneres. Aceitam-se, também, livros para divulgação, elaboração de resenhas e recensões.

Toda correspondência, material para publicaçăo (vide normas na terceira capa), assinaturas e permutas devem ser dirigidos ao seguinte destinatário:

PROF. NALI DE JESUS DE SOUZA

Revista Análise Econômica

Av. Joảo Pessoa, 52

CEP 90040-000 PORTO ALEGRE - RS, BRASIL.

Telefones: (051) 316-3348 e 316-3440

Fax: (051) 225-1067 


\section{PADRÕES MONETÁRIOS ALTERNATIVOS: CONSIDERAÇÕES SOBRE O CASO BRASILEIRO}

Fernando Carlos G. de Cerqueira Lima*

\section{SINOPSE}

Este artigo analisa as principais caracteristicas, as dificuldades e os riscos inerentes à adoçäo de duas formas de áncora cambial e duas formas de âncora monetária no Brasil. São apresentadas, em particular, a âncora cambial propriamente dita - a mera fixação da taxa de câmbio frente ao dólar, assim como a âncora nominal, que inclui a conversibilidade. Dentre as âncoras monetárias, são discutidas a criação de um Banco Central independente e o estabelecimento de regras de expansão monetária

\section{INTRODUÇÃO: ÂNCORAS E PADRÕES MONETÁRIOS}

Nos últimos anos, a inflação brasileira tem sido combatida em duas frentes: de um lado, utilizam-se os instrumentos ortodoxos de combate à inflação, como o aperto fiscal e taxas de juros elevadas; e, por outro lado, prepara-se o terreno para a implantação de um plano de estabilização, que incluiria tanto medidas heterodoxas, tais como a adoção de algum tipo de âncora. $O$ papel fundamental dessa âncora seria o de alargar o horizonte de cálculo dos agentes econômicos, i.e., de oferecer uma referência estável, em termos nominais, para os contratos. Mas qualquer das âncoras que vier a ser adotada - agora ou no futuro - representará uma mudança de padrão (ou regime) monetário, definido como forma de controle e administração da moeda, devendo, idealmente, ser mantida por um longo periodo. ${ }^{1}$

A escolha da âncora é um aspecto essencial para o rápido sucesso ou fracasso de qualquer plano de estabilização, mas também é capaz de trazer conseqüências duradouras: o acerto na escolha pode trazer a desejada queda acentuada na inflação, mas uma escolha equivocada adiaria a estabilização por mais alguns anos, podendo até mesmo causar uma aceleração inflacionária tão logo os agentes econômicos se apercebessem da inviabilidade do plano.

O descrédito da moeda nacional tem popularizado a idéia de dolarização. Mas este é um conceito cuja definição está sujeita a controvérsias (Carvalho, 1992). Pode representar a simples permissão para que o dólar seja usado como indexador de contratos, como pode representar a fixação da taxa de câmbio (âncora cambial) sem conversibilidade ou mesmo permitindo a conversibilidade (âncora nominal). A conversibilidade plena - desde que com o câmbio fixo - significaria, na prática, o retorno às regras do padrão-ouro, agora padrão-dólar. Poderịa haver ainda conversibilidade com câmbio flexível. Outra forma de dolarização seria a autorização de abertura de contas em moeda estrangeira, com ou sem a adoção de âncoras. Ou ainda, adotando-se a conversibilidade plena, poderíamos ter um Conselho da Moeda como autoridade monetária exclusiva.

* Doutor pela Universidade do Pais de Gales e Prof. Adjunto do Dep de Economia da UFRJ

\begin{tabular}{|c|c|}
\hline $\begin{array}{c}\text { Cód. AEA } \\
\mathbf{3 1 0}\end{array}$ & $\begin{array}{c}\text { Palavras-chave: âncora cambial, âncora monetária, } \\
\text { padróes monetários }\end{array}$ \\
\hline
\end{tabular}

\begin{tabular}{|l|c|c|c|}
\hline ANÁLISE ECONÔMICA & ANO 12 & março/setembro 95 & p. 47-65 \\
\hline
\end{tabular}

1 Sobre a definição de padrão monetário e algumas das alternativas disponiveis nos paises mais desenvolvidos, ver Goodhart (1992) 
Entretanto a adoção de um padrão monetário ancorado em uma moeda externa não é a única opção disponível. A escolha de uma "âncora monetária" - baseada, portanto, na moeda nacional - tem sido proposta por defensores da tese de um Banco Central independente ou mesmo de uma - também vagamente definida constituição monetária em que as autoridades monetárias se veriam forçadas a perseguir uma determinada meta de expansão dos meios de pagamento prefixada.

As âncoras cambial, nominal e monetária, em suas diversas versões, têm sido as mais citadas como instrumentos para se combater a atual escalada de preços no Brasil e, mesmo, para se atingir uma estabilidade duradoura no futuro. Nesse sentido, este texto analisa dois tipos de âncora externa - a âncora cambial, a âncora nominal -, dois tipos de âncora monetária - um Banco Central independente e a fixação de regras fixas de expansão monetária - não apenas como instrumentos de curto prazo, para se obter a estabilização, mas também sua viabilidade como regime monetário no longo prazo.

\section{2. ÂNCORA CAMBIAL}

\subsection{Algumas precondições}

A adoção de uma âncora cambial hoje em dia significaria o estabelecimento de algum tipo de relação, mais ou menos fixa, entre a moeda nacional e uma moeda externa - no caso dos países latino-americanos, o dólar. A fixação dessa paridade poderia se dar de, pelo menos, três formas distintas: i) poderia ser estabelecida uma paridade única, considerada imutável, como fez a Argentina em 1991; ii) a taxa de câmbio poderia flutuar dentro de uma determinada faixa, como ocorre no combalido Sistema Monetário Europeu; iii) por fim, poderia ser prefixada - por exemplo, a taxa de desvalorização da moeda nacional seria determinada com antecedência, sendo o percentual inferior ao da inflação, como tem sido feito no México Esta seção aborda basicamente o primeiro caso, i.e., da fixação da taxa de câmbio do cruzeiro frente ao dólar, embora entendamos que as conclusões sejam aplicáveis aos outros dois casos. Em ambas as hipóteses, estamos tratando de taxas de câmbio nominais, em contraste com taxas de câmbio reais.

$\mathrm{Na}$ área externa, o anúncio da adoção de uma âncora cambial deveria, idealmente, ser precedido de uma boa dose de liberação do comércio exterior, de um grande acúmulo de reservas internacionais e de uma política cambial realista. A abertura lenta e gradual da economia à concorrência internacional já em operação permitiria que as empresas nacionais (e mesmo as estrangeiras aqui instaladas) alcançassem um nível suficiente de competitividade, enquanto que a adoção de uma taxa de câmbio nem sobrevalorizada nem depreciada permitiria que a fixação da paridade se desse sem traumas. Isso quer dizer que não haveria necessidade de se promover uma súbita desvalorização cambial no momento do lançamento da âncora, o que certamente traria pressões inflacionárias no futuro próximo ${ }^{2}$ Por outro lado, possuir reservas suficientes é essencial para dar credibilidade à

\footnotetext{
2 Essa questão foi levantada por Franco (1993), que afirma que a sobrevalorizaçäo do câmbio argentino um dos principais problemas do Plano Cavallo - è na verdade anterior ao Plano, e não apenas resultado da inflação "residual"
} 
âncora $^{3}$ É preciso que os especuladores dos mercados de câmbio sintam que o governo tenha cacife para enfrentar qualquer corrida contra a moeda nacional; é preciso também haver uma margem suficientemente confortável para o caso de haver, inicialmente, déficits na balança comercial ou mesmo fuga de capitais.

Essas precondições são fundamentais para conferir credibilidade à âncora Em outras palavras, é essencial que os agentes acreditem no sucesso duradouro de um plano de estabilização ancorado em um câmbio fixo. Isso só é possível quando existe convicção de que a taxa de câmbio, uma vez estabelecida, pode ser sustentada. Para tanto, é necessário que o pais não enfrente maiores dificuldades no balanço de pagamentos. Por outro lado, certamente aflorariam sérias pressões políticas para a revisão da taxa de câmbio, caso o plano provocasse um prolongado periodo de recessão e de desemprego

\subsection{Riscos da taxa de câmbio fixa}

No combate a uma inflação como a brasileira, uma grande vantagem do câmbio fixo é abrir espaço para o estabelecimento de contratos de longo prazo, já que os agentes econômicos passam a contar com um referencial estável. Havendo credibilidade suficiente na política, a queda da inflação poderia ser instantânea. Além disso, se a âncora cambial fosse lançada em um momento em que o nível das reservas internacionais fosse considerado adequado, o preço dos tradables - ou seja, dos produtos que participam da pauta de exportação e importação - não poderia ser superior ao praticado no comércio internacional, já que sofreriam a livre concorrência das importações. Dessa forma, quanto maior a abertura da economia, i.e., quanto maior a participação dos tradables no produto nacional, mais perto se situaria a inflação do Brasil da inflação internacional

No caso brasileiro, é exatamente esse um dos maiores riscos da âncora cambial. Como o nosso grau de abertura é bastante reduzido, é difícil prever como se comportaria a taxa de inflação, já que a grande maioria dos produtos são nontradables. Se o preço desses produtos - que não estão sujeitos à concorrência internacional - continuasse a se comportar como antes, o nível geral de preços continuaria a se elevar, mesmo que a uma taxa inferior. ${ }^{4}$ Como o custo das empresas estaria sendo afetado por esses produtos, e o preço dos tradables estaria limitado pelo preço internacional, as empresas brasileiras perderiam competitividade, enquanto que os produtos importados ficariam cada vez mais baratos. A crise da balança comercial seria inevitável. Igualmente inevitáveis seriam a recessão e o desemprego, principalmente no setor secundário.

Ceteris paribus, um déficit nas transações correntes acarreta perda nas reservas internacionais. Ter-se-ia então que contrabalançar essa situação com superávites na conta de capital. Este só seria alcançável se houvesse, ao mesmo tempo, uma elevação da taxa de juros interna e uma disposição dos aplicadores em trazer - o que quer dizer, na maioria das vezes, trazer de volta - capitais externos. Mais precisamente, a taxa de juros praticada no mercado financeiro brasileiro precisaria

\footnotetext{
3 Wilianson (1989) analisa alguns dos principais fatores determinantes da demanda por reservas internacionais, destacando seu papel de absorvedor de choques externos

${ }_{4}^{4}$ Esse problema poderia ser minorado, no entender de Franco (1993), com a decretação de algum mecanismo de administraçäo de preços, um semicongelamento dos nontradables e de algumas tarifas, embora reconhecendo as dificuldades práticas de tal medida
} 
ser consideravelmente superior à praticada nos mercados internacionais (particularmente, nos EUA); e, por outro lado, a confiança do investidor estrangeiro (ou brasileiro), fundamental para que esses capitais sejam aplicados internamente, dependeria em grande parte na confiança de que a taxa de câmbio pudesse ser mantida. Quanto menor a confiança, maior o prêmio exigido, ou seja, maior a taxa de juros para compensar o risco (real ou imaginário) da desvalorização cambial. Desnecessário dizer que, quanto maior a taxa de juros, maior a recessão e mais elevados os custos financeiros das empresas e do governo, podendo com isso agravar a inflação.

\subsection{Implicações para a política econômica}

Note-se que as pressões inflacionárias, neste caso, estariam ocorrendo independentemente de a política monetária estar sendo ou não deliberadamente restritiva. A elevação dos juros poderia estar sendo motivada não necessariamente porque o estoque monetário estaria se elevando acima do desejado, mas pela necessidade de atrair capitais externos - possivelmente de curto prazo - com o objetivo de manter a paridade da moeda nacional Em outras palavras, a política monetária deixa de ter como objetivo o controle dos preços, voltando-se exclusivamente para a manutenção da taxa de câmbio. Mais ainda, e de acordo com o modelo Mundell-Fleming, taxas de câmbio fixas em economias abertas fazem com que a oferta de moeda seja determinada endogenamente, tornando inoperante a política monetária (Dornbusch e Fisher, 1991). Quando as autoridades monetárias adotam uma política restritiva visando reduzir a expansão da moeda, para combater a inflação e para impedir a desvalorização, a taxa de juros se eleva, atraindo recursos externos que, ao serem convertidos internamente, acarretam o aumento de liquidez que de início buscava-se evitar. Dessa forma, persistiria a tendência ao desequilibrio do balanço de pagamentos, com o agravante de elevar-se a dívida externa. $^{5}$

Contudo, se a política monetária torna-se inoperante, o mesmo não se pode dizer da política fiscal. No front interno, e particularmente no caso brasileiro, a adoção de uma âncora cambial exigiria o prosseguimento - ou o aprofundamento do ajuste fiscal. A idéia central, nessa questão, seria impedir que o setor público se tornasse um fator adicional de pressão de demanda e permitir a "esterilização" da moeda criada a partir do superávit comercial sem elevação da taxa de juros, já que esta elevação, como vimos, acaba por trazer ainda mais recursos de fora, elevando a base monetária. ${ }^{6} \mathrm{Na}$ ausência do ajuste fiscal, e particularmente no caso de o

\footnotetext{
${ }^{5}$ A inoperância da política monetária com taxas de câmbio fixas é uma das principais razões pela qual os economistas de linha monetarista defendem a adoção de taxas de câmbio flutuantes A respeito, ver, entre outros, Laidler (1982) e Friedman (1983). Por essa visão, não haveria o "problema do balanço de pagamentos". Se a demanda por moeda estrangeira aumenta, seu preço, na ausência de um proporcional aumento da oferta, também irá se elevar, como acontece com qualquer mercadoria. A demanda se ajustaria à oferta via alterações na taxa de cámbio

6 A idéia de a que adoção de uma âncora cambial seria capaz, por si só, de impor uma "camisade- força" ao governo, obrigando-o a equilibrar suas finanças, não parece encontrar suporte nas evidências históricas. Em vários países, o governo continuou a registrar déficits, acarretando a posterior revisão da taxa de câmbio. Nos países que conseguiram manter a taxa de câmbio fixa,
} 
Banco Central prosseguir financiando indiretamente o Tesouro, a manutenção da taxa de câmbio é virtualmente impossível. Mais ainda, a simples percepção, por parte da opinião pública, de que as contas do governo continuam fora de controle seria suficiente para fazer com que a âncora cambial näo tivesse credibilidade já no seu lançamento. Nesse caso, assim como em um outro mais famoso, não basta simplesmente ser, é essencial também parecer.

\subsection{A questão da indexação}

O sucesso da âncora cambial dependeria ainda da proibição de todas as formas de indexação pela inflação, corrente e passada, particularmente dos salários. Todo o esforço deveria ser realizado no sentido de que os contratos fossem indexados ao câmbio, sob o risco de alimentar defasagens nos preços relativos. Isso significaria criar mecanismos jurídicos para impedir recomposição de perdas. Simonsen (1993) aponta a dificuldade, em termos de desequilíbrio do balanço de pagamentos, que representaria uma elevação em dólar dos salários. Esse desequilibrio poderia ser entendido como proveniente tanto de um aumento do custo das empresas e dos gastos públicos, como por um aumento da demanda agregada, ambos repentinamente e em termos reais. Na Argentina, tal pressão sobre os salários não teria ocorrido. A questão da defasagem de preços, evidentemente, não se prende apenas aos salários. Seria indispensável que as tarifas públicas estivessem em um nivel razoável antes do plano de estabilização, para evitar "tarifaços" que fatalmente trariam problemas de custo mais tarde. O mesmo diz respeito aos preços controlados, especialmente das empresas estatais. Em qualquer dos casos, ter-seia de evitar recomposições de preços no momento da adoção da âncora, assim como reajustes posteriores em função da inflação; ou seja, tem-se de evitar a indexação, tanto em relação à inflação passada como em relação à futura. ${ }^{7}$

\subsection{Resumo}

O sucesso da adoção de uma âncora cambial, entendida simplesmente como a fixação de uma paridade fixa entre o cruzeiro real e o dólar, estaria na dependência do atendimento de uma série de precondições, as principais delas sendo um forte ajuste fiscal, o estabelecimento de tarifas públicas realistas e de uma taxa de câmbio com uma folga suficiente para suportar uma inevitável inflação residual e, ainda, o acúmulo de reservas internacionais suficientes para convencer os agentes - e principalmente os participantes dos mercados cambiais - de que eventuais choques externos, ou mesmo uma (moderada) sobrevalorização do cruzeiro, poderiam ser facilmente absorvidos. Isso tudo antes do lançamento da âncora. Após a entrada em vigor do novo padrão monetário, seria necessário manter o aperto fiscal e cuidar para que não se verificassem recomposições de preços,

- governo já havia mostrado empenho ern seguir uma política de austeridade fiscal antes da adoção da âncora. Ver, a respeito, Corden (1993).

7 Deve-se notar que, em geral, nos paises que fixaram sua moeda a outra mais forte, a inflação registrada tem sido sistematicamente superior à do país da moeda âncora, ocasionando a sobrevalorização da moeda nacional e a conseqüente perda de competitividade (Végh, 1992). 
incluindo salários 8 A política monetária estaria voltada unicamente à manutenção da paridade cambial, o que significa dizer que provavelmente os juros teriam de ser mantidos elevados, a não ser que as condições externas - i.e., a entrada líquida de recursos - se mostrasse sempre favorável.

A questão central - e isso é válido também para qualquer das outras hipóteses de padrão monetário aqui analisadas - é a da credibilidade A credibilidade depende, por sua vez, de como os agentes interpretam as ações do governo. Estas, como não poderia deixar de ser, estão sujeitas às mais variadas pressões políticas. As mais óbvias são aquelas advindas das conseqüências econômicas, sociais e políticas (eleitorais) de uma possível prolongada recessão e aumento do desemprego. A credibilidade estaria também ameaçada pela reação a choques externos, como queda do preço das mercadorias exportadas, elevação súbita de preços de produtos importados de difícil substituição e do comportamento da taxa de juros praticadas nos mercados financeiros internacionais. Ao primeiro sinal de fraqueza - medida em termos das pressões anti-recessivas e pelo nivel das reservas internacionais - haveria uma corrida contra a moeda nacional. $E$, nesse caso, como ocorria com o padrão-ouro clássico, o único instrumento nãointervencionista de defesa da paridade seria a elevação da taxa de juros, o que, convenhamos, não é muito diferente do que tem ocorrido nos últimos anos, além de nem sempre resolver o problema. ${ }^{9}$

As outras formas de manter a paridade seriam o controle do câmbio, com todas as suas consequêencias de longo prazo, ou ainda a imposição de restrições às importações, através de quotas ou tarifas Mas a manutenção a todo custo da paridade cambial acabaria por afetar substancialmente a política industrial que se pretende mais aberta e mais competitiva internacionalmente.

\section{DOLARIZAÇÃO OU ÂNCORA NOMINAL}

\subsection{Sobre o conceito de conversibilidade}

O conceito de dolarização que utilizamos aqui refere-se à âncora cambial analisada acima, acrescida do fato de que a moeda nacional torna-se plenamente conversivel. A dolarização, ou âncora nominal, possui assim duas características distintas: paridade fixa com o dólar e conversibilidade plena do cruzeiro (Belluzzo e Almeida, 1992). Também o conceito de conversibilidade é um tanto dúbio. Findo o uso monetário do ouro, i.e., não havendo mais a possibilidade prática de se utilizar

\footnotetext{
${ }^{8}$ Essa última condição taivez seja a que mais independe da vontade do Poder Executivo, uma vez que este tem de se sujeitar às decisões do Judiciário quanto às ações trabalhistas e outras

${ }_{9} \mathrm{O}$ exemplo da experiência inglesa e italiana quando da crise do Sistema Monetário Europeu (SME), em 1992 e 1993, é esclarecedor Apesar da elevação dos juros, què trouxeram forte desaceleração da economia, e das constantes declarações de seus governantes de que a taxa de câmbio seria mantida dentro da faixa de variaçäo acordada em 1989, ambos os paises acabaram sendo eventualmente forçados a desvalorizar suas moedas e a abandonar o SME Isso após duras batalhas com os especuladores dos mercados de cambio durante as quais suas reservas internacionais foram seriamente reduzidas. Outro exemplo foi dado pela Suécia que, apesar de não pertencer formalmente ao SME, ancorava sua moeda no marco alemão. Durante a crise, seu banco central chegou a praticar taxas overnight de $500 \%$ ao ano, talvez como uma forma desesperada de mostrar sua determinaçäo de manter a paridade preestabelecida Mas, como nos casos da Itália e GB, teve de aceitar a depreciação de sua moeda, além de também perder boa parte das reservas
} 
o ouro como âncora, o dólar passou a fazer as vezes de âncora universal. ${ }^{10}$ Mas pode-se perguntar o que significaria efetivamente decretar a conversibilidade do cruzeiro real? Em que sentido o cruzeiro seria mais conversivel do que já é hoje em dia? Afinal, as casas de câmbio fazem essa conversão livremente, e a cotação dessas transações são anunciadas todos os dias pelos meios de comunicação. $O$ cruzeiro não é considerado uma moeda conversível internacionalmente, no sentido de que não é objeto de negociação em outros mercados de câmbio. Mas a libra esterlina, por exemplo, embora (ainda) tenha ampla aceitação globalmente, não tem sua conversibilidade garantida pelo governo, assim como o governo dos EUA não assegura a nenhum portador de dólares sua conversibilidade em outra moeda.

Friedman (1962) chama a atenção para essa distinção. A conversibilidade pode se dar porque o governo se compromete a converter a moeda do país em outra (ou em uma mercadoria) ou porque o mercado cumpre essa função. O sentido de conversibilidade que utilizamos refere-se ao primeiro caso, com uma importante adição: a moeda torna-se conversivel a uma taxa de câmbio fixa especificamente em relação ao dólar. Note-se que, embora haja sempre uma taxa de mercado para transações entre as duas moedas, a manutenção de uma dada taxa de câmbio e da própria conversibilidade pelo governo dependerá de uma série de fatores, como se verá a seguir. Se os agentes acreditarem que a paridade fixada pelo governo é irrealista - ou seja, tende a se afastar cada vez mais da taxa de mercado - a abolição tanto da paridade como da conversibilidade será uma questão de tempo. $E$ quanto mais tempo o governo resistir, maior será o custo em termos de perdas de reservas oficiais.

\subsection{Dolarização versus âncora cambial}

Alguns dos problemas com a dolarização são, portanto, equivalentes ao da âncora cambial Haveria necessidade de um forte ajuste fiscal e principalmente de evitar a monetização desse déficit, já que seria de crucial importância impedir que se elevasse a proporção de moeda nacional em relação à moeda âncora. Para evitar a sobrevalorização da moeda seria preciso extinguir todo tipo de indexação, passada, presente e futura. $E$ a taxa de juros constituir-se-ia no instrumento básico de ajuste, pelo menos se considerarmos apenas os instrumentos "de mercado", i.e., excluirmos controles cambiais e de importações, confiscos diversos, etc.

Mas há diferenças. Uma é favorável: a conversibilidade, com credibilidade, representaria a noção de âncora com mais clareza. Ou seja, as vantagens da âncora cambial seriam realçadas e os efeitos da estabilização seriam mais rapidamente sentidos. O cruzeiro passaria a ser uma mera representação do dólar, com as duas moedas podendo ser utilizadas uma em substituição à outra. E se o grau de abertura externa fosse ampliado, seria mais difícil a ocorrência de uma inflação em dólares. Outras diferenças, contudo, representam desvantagens. Uma delas diz respeito à aparente irreversibilidade da dolarização. Estudando algumas experiências latino-americanas, Baptista Jr. (1993) concluiu que o processo de substituição da moeda nacional aprofundou-se após a estabilização, ao invés de haver regredido, como muitos esperavam. Esse problema teria conseqüencias imprevisiveis, já que, como se sabe, "a soberania monetária é um elemento

${ }^{10}$ No caso da América Latina e outras áreas Mas também o marco alemão tem sido usado como âncora, principalmente na Europa, e o iene japonês deverá seguir o mesmo caminho, a começar pela Ásia. 
essencial da soberania nacional" (idem, p.17).

\subsection{A questão das reservas internacionais}

A segunda desvantagem da dolarização é uma questão mais imediata e referese ao volume de reservas campativel com a manutenção da conversibilidade. A situação ideal seria aquela em que as reservas internacionais fossem suficientes para converter todo o dinheiro em circulação. A primeira dificuldade aqui está em definir "dinheiro". Que variável seria utilizada nesse cálculo: a base monetária, como no caso da Argentina? No Brasil isso seria insuficiente, por duas razões. Por um lado, a proporção base/PIB tem-se mostrado extremamente baixa - cerca de $1 \%$ - em conseqüência principalmente da própria inflação. Entretanto existe um imenso potencial de conversão do total de liquidez financeira - incluída no conceito de M4 em base monetária, historicamente situada entre $20 \%$ e $25 \%$ da renda nacional. Essa imensa diferença quantitativa entre os dois conceitos de meios de pagamento não se verificava na Argentina quando da decretação da conversibilidade, em 1991 Outra razão é que a estabilização dos preços, conforme atesta a experiência brasileira após os primeiros choques heterodoxos, deverá acarretar uma substancial modificação na composição dos ativos líquidos, com o crescimento da participação tanto da base monetária como de M1 - ie., papel moeda em circulação mais depósitos à vista - no total dos ativos financeiros.

Note-se, portanto, que, pelo menos potencialmente, a quantidade de meios de pagamento passível de conversão em dólares - para a qual o governo deveria estar preparado, sob pena de perder credibilidade na imposição da âncora nominal - pode chegar a $1 / 4$ do PIB. Isso significaria, considerando-se um PIB de US $\$ 400$ bilhões, que o nível ideal de reservas estaria em torno de US $\$ 100$ bilhões, nivel este virtualmente impossivel de ser atingido ${ }^{11}$

Assim, descontando-se a hipótese de se repetir o confisco do Plano Collor, a dificuldade com a conversibilidade poderia ser considerada um problema de origem. Isso não quer dizer, é claro, que a âncora nominal estaria condenada ao fracasso em função apenas do problema da insuficiência de reservas, mesmo porque desconhece-se qual a exata proporção dos ativos financeiros não-monetários que seriam monetizados. Quanto mais elevada a taxa de juros dos títulos denominados em cruzeiros, menor seria a demanda por meios de pagamento tradicionais (M1) e, portanto, menor o risco potencial de colapso da conversibilidade. O nível dos juros necessário para impedir uma monetização excessiva iria variar de acordo com as mudanças nas expectativas dos agentes em relação à manutenção da conversibilidade, na mesma direção que as necessidades de elevar o nível das reservas. De qualquer modo, representaria um complicador adicional na execução da política monetária que, assim como ocorreria no caso da âncora cambial, estaria totalmente voltada a questões cambiais, e não à administração da relação entre liquidez interna e atividade econômica.

\subsection{A emissão da moeda conversível: o papel do conselho da moeda}

Uma discussão pertinente à proposta da conversibilidade é quanto ao órgão

\footnotetext{
${ }^{11}$ Franco (1993) calcula esse nivel ideal em 84 bilhões de dólares, considerando que a média histórica da relação ativos financeiros/PIB no Brasil é de $30 \%$, mas que parte das reservas - cerca de $30 \%$ - poderia ser constituida de "bonex", no estilo argentino
} 
emissor da moeda conversivel ou, se a emissão continuar a ser feita pelo Banco Central, quanto à forma de conversibilidade. As opções são várias. A mais realista de todas seria a simples garantia de conversibilidade de todo o estoque de moeda em circulação. Seria criada uma entidade especialmente para esse fim, que chamaremos de Conselho da Moeda, assim como já se chamou Caixa de Conversão, mas que só operaria diretamente com o sistema bancário. Este cuidaria das demandas do público por dólares, aceitando depósitos denominados na moeda norte-americana. O Conselho da Moeda não teria as funções típicas de Banco Central, atuando simplesmente na conversão entre a moeda nacional e a que serve de âncora (e vice-versa). A criação desse Conselho representaria uma garantia de que não seria possível monetizar eventuais déficits orçamentários, sendo este o sentido de considerá-lo "independente". Entretanto essa "independência" evidentemente não se aplica à obrigatoriedade de emissão em tróca de cambiais.

\section{BANCO CENTRAL INDEPENDENTE COMO ÂNCORA MONETÁRIA}

\section{1 Âncora monetária versus âncora cambial}

Uma solução alternativa à âncora externa é a âncora monetária: a adoção de medidas que fortaleçam a moeda nacional sem que esta esteja atrelada a uma moeda "forte". A âncora monetária pode assumir duas formas distintas, embora não excludentes. Por um lado, poderia representar a criação de um banco central de fato independente, como o Bundesbank (Banco Central alemão), capaz de resistir a pressões políticas no cumprimento de seu objetivo único, qual seja, inflação zero ou muito próxima disso. Outro exemplo de âncora monetária seria a adoção de regras fixas de expansão do estoque de meios de pagamento, como tem sido proposto por monetaristas da linha de Milton Friedman e dos adeptos da escola das expectativas racionais $\hat{E}$ importante realçar que essas duas formas podem coexistir simultaneamente, no caso de o banco central, uma vez independente, optar por estabelecer percentuais fixos de expansão dos meios de pagamento como meta intermediária da política monetária ${ }^{12}$ A expressão "âncora" ganha, nesse caso, uma conotação psicológica ainda mais acentuada que no caso da âncora cambial, representando uma fé inabalável de que exista uma relação direta entre austeridade monetária e estabilização de preços ou, pelo menos, de que essa seria a expectativa dos agentes econômicos. Esta seção trata de questões relacionadas à criação de um Banco Central independente $(\mathrm{BCl})$, enquanto que o estabelecimento de regras monetárias constantes será analisado na próxima seção.

\subsection{Definição de $\mathrm{BCl}$}

Antes de mais nada, cumpre caracterizar um $\mathrm{BCl}$ ou, mais exatamente, definir o que vem a ser essa "independência". Afinal, um $\mathrm{BCl}$ seria independente do quê? A resposta mais simples é que a independência pretendida para o Banco Central é com relação ao governo - em todos os niveis, i.e., federal, estadual e municipal. $O$ $\mathrm{BCl}$ estaria proibido - ou, pelo menos, desobrigado - de financiar, mesmo que indiretamente, déficits orçamentários, permitindo a elevação da taxa de juros até o ponto em que a oferta e a demanda de recursos liquidos se equilibrasse no mercado monetário. Essa situação contrasta fortemente com a experiência histórica

\footnotetext{
${ }^{12} \mathrm{Em}$ contraste com outras metas, como p ex a administração da taxa de juros, controle de crédito, etc.
} 
brasileira, em que o Banco Central - e antes dele o Banco do Brasil - acabava por atender às deficiências de caixa do governo federal e, muitas vezes; também das outras esferas governamentais.

Nesse sentido, um $\mathrm{BCl}$ imporia a austeridade orçamentária, da mesma maneira que o Conselho da Moeda. Isso não quer dizer, entretanto, que o governo não possa eventualmente incorrer em gastos superiores à sua receita, mas sim que, se o fizer, terá que arcar com o ônus, inclusive político, de trabalhar com taxas de juros mais altas. Dessa maneira, torna-se bastante limitado o uso da política fiscal como instrumento de incentivo à atividade econômica. Ou, como preferem dizer os "antipopulistas", torna-se difícil o uso do imposto inflacionário para fins políticos. Nesse sentido, há quem acredite que um $\mathrm{BCl}$ seja capaz de impor "constrangimentos" à atuação do governo na área fiscal (Burdekin e Laney, 1988).

Outra faceta da independência do Banco Central diz respeito à autonomia de sua diretoria na formulação da política monetária. Sendo constitucionalmente incumbido de defender o poder de compra - interno e externo - da moeda, um $\mathrm{BCl}$ deve ignorar apelos e pressões, tanto do governo como dos variados lobbies, no sentido de alterar suas metas de acordo com a conjuntura econômica. Particularmente, um $\mathrm{BCl}$ deve apertar a política monetária sempre que sentir que as pressões inflacionárias estão se avolumando, mesmo que isso implique um desaquecimento da economia. A atitude do Bundesbank durante a crise gerada pela unificação alemã e, mais recentemente, quando do colapso do Sistema Monetário Europeu em 1992-3, é reveladora. Apesar de toda pressão interna e dos paises membros do SME, o Bundesbank não abandonou sua política de austeridade, mantendo a taxa de juros em niveis sempre mais elevados do que desejam os políticos e as lideranças empresariais e sindicais.

A razão de ser de um $\mathrm{BCl}$ encontrar-se-ia, dessa maneira, no fato de ter uma preocupação com a estabilidade no longo prazo, enquanto que o governo, como qualquer governo, está mais preocupado com as próximas eleições. O Tesouro Nacional sofreria de miopia, enquanto que o $\mathrm{BCl}$ enxergaria de longe (Lombardini, 1992) Esta é, entretanto, uma questão no mínimo polêmica. Afinal, um governo via de regra é eleito, e pode ser eleito com uma plataforma que privilegie, por exemplo, combater o desemprego, ou que esteja comprometido em levar adiante projetos que os eleitores considerem essenciais. Mesmo que tenha a intenção de fazer cumprir suas promessas eleitorais, o governo poderia se defrontar com a atitude de confrontação da parte do $\mathrm{BCl}$ que, através de uma política monetária restritiva, poderia impedir o governo de realizar os gastos prometidos. Nesse sentido, teme-se que um $\mathrm{BCl}$ torne-se um "quarto poder". Por outro lado, como explica Holtham (1993), se uma determinada sociedade privilegia a estabilidade dos preços e teme pelas atitudes inflacionistas de seus governantes, talvez fizesse mais sentido estabelecer uma autoridade fiscal independente, ao invés de uma autoridade monetária independente, já que a política fiscal tem sido mais utilizada para fins eleitoreiros do que a política monetária. ${ }^{13}$ Segundo Holtham, a pressão que se verifica a favor de se conceder maior autonomia para os bancos centrais tem mais a ver com razões de ordem política - limitar o poder do Estado - do que fundamentos econômicos - i.e., obter a queda da inflação a um custo inferior.

A independência do Banco Central, entretanto, deve ser qualificada Uma

${ }^{13}$ Esse argumento também é apresentado por Arcelli (1992) 
"constituição monetária" que crie um $\mathrm{BCl}$ deve explicitar suas responsabilidades, assim como deve nomear o órgão encarregado de verificar se suas atribuições legais estão sendo devidamente observadas. ${ }^{14}$ Além da questão da probidade de seus diretores, esse órgão - preferencialmente o Parlamento - deve julgar o desempenho do $\mathrm{BCl}$ exclusivamente pelos seus resultados, i.e., pela sua capacidade de manter a estabilidade dos preços. Um $\mathrm{BCl}$, portanto, deve explicações à sociedade e, por esse motivo, muitos preferem a expressão "autonomia" ao invés de "independência".

\subsection{Mensurando a relação entre $\mathrm{BCl}$ e inflação}

A defesa da tese de que um $\mathrm{BCl}$ é um importante fator de estabilização tem sido discutida nos últimos dez anos, especialmente por aqueles que também acreditam que a estabilidade dos preços é um importante fator de crescimento econômico. Estudos econométricos têm sido publicados relatando a validade dessas relações ${ }^{15}$ Entretanto deve-se tomar cuidado com análises desse tipo, por pelo menos duas razões. A primeira razão diz respeito à dificuldade de se determinar se é a independência do $\mathrm{BC}$ que permite a um país registrar baixos índices de inflação, ou vice-versa. ${ }^{16}$ Como argutamente afirmou Eugênio Gudin (1972, p.273), "não tem um banco central (independente) quem quer, e sim quem já atingiu um padrão mínimo de ordem financeira e administrativa capaz de permitir o seu financiamento eficaz". $\mathrm{E}$, nesse caso, não precisariam de um $\mathrm{BCl}$. Em outras palavras, os países que possuem um $\mathrm{BCl}$ são aqueles que por tradição estão mais preocupados com a inflação, i.e., cujas instituições aceitam a primazia da estabilidade dos preços. Assim, não seria o fato de possuírem um $\mathrm{BCl}$ que faria com que registrassem baixos níveis de inflação, mas o contrário. Esse é o caso típico da Alemanha desde a reforma monetária de 1948. Mas o exemplo do Japão parece desmentir a relação BCl-inflação baixa: o Banco Central japonês não passa de mera repartição do Ministério da Fazenda, mas aquele país também vem registrando baixos índices inflacionários.

A segunda dificuldade para se determinar a validade da relação entre $\mathrm{BCl} e$ inflação baixa é que não existe consenso quanto à melhor forma de se mensurar o grau de independência de um Banco Central. Eijfinger e Schaling (1993) chamam a atenção para o fato de que qualquer classificação de independência dos diferentes bancos centrais é necessariamente arbitrária A questão chave está relacionada com os aspectos formais da independência. O Federal Reserve dos Estados Unidos é considerado um modelo de independência, mas há quem conteste essa independência na prática. Kane (1980), por exemplo, assegura que, apesar de sua

\footnotetext{
${ }^{14}$ Segundo um crescente número de banqueiros centrais, a responsabilidade primeira, e talvez única, de um BCl, é obter a mais baixa taxa de inflação possivel (Bruni e Monti, 1992). Tradicionalmente, entretanto, os livros-texto afirmavam que o "objetivo último" da política monetária e, portanto, do Banco Central seria obter a mais alta taxa de crescimento econômico e o mais baixo nivel de desemprego possiveis com estabilidade dos preços (Samuelson, 1975). Essa não é simplesmente uma questão de semántica, já que simboliza a eterna disputa entre "monetaristas" e "keynesianos", na conceituação um tanto livre que Kindleberger (1978) apresenta dessas duas linhas de pensamento

${ }_{15}$ Ver, por exemplo, Long e Summers (1992) e Haan e Sturm (1992) Esses estudos concluem que não apenas existe uma forte correlaçăo inversa entre independência do Banco Central e inflaçăo, mas também uma correlação positiva entre $\mathrm{BCl}$ e crescimento econômico.

${ }_{16}$ Esse é um dilema semelhante ao que cerca a relação entre variações do estoque de moeda e o nivel de preços
} 
aparente soberania, o FED modifica sua estratégia em momentos considerados estrategicamente críticos para o governo e poderosos lobbies ${ }^{17} \mathrm{O}$ oposto ocorre com o Banco do Japão, formalmente sem qualquer independência, mas que tem se conduzido de maneira aparentemente autônoma nos últimos anos.

\subsection{Funções de um $B C I$}

Uma questão recorrente na literatura sobre independência do Banco Central é concernente às funções que deveria desempenhar. Como mencionou-se anteriormente, caberia ao Parlamento definir as atribuições do $\mathrm{BCl}$ e cuidar para que essas atribuições fossem cumpridas a contento. Para muitos analistas, essas funções deveriam ser reduzidas ao mínimo possivel, o que Bruni (1992) chama de "purificação" dos bancos centrais. Uma função óbvia seria cuidar da estabilidade do poder de compra da moeda, e sobre essa função parece haver consenso, ainda que exista discordância sobre a melhor maneira de se atingir essa estabilidade. Mas restaria discutir a questão de se um $\mathrm{BCl}$ deveria ou não regular e fiscalizar as instituições financeiras.

Para Goodhart (1988), as autoridades monetárias devem cumprir duas funções. uma função macro, que é a de administrar a moeda, no sentido de controlar sua emissão e a taxa de juros. A segunda é uma função micro, qual seja, a de cuidar da saúde do sistema financeiro. Historicamente, a função micro tem prevalecido, e é ela que explica a própria criação de bancos centrais hoje independentes, como o Federal Reserve. A função de emprestador de última instância é uma das mais importantes do Banco Central, e a noção, por parte das instituições financeiras, de que o sistema como um todo será socorrido sempre que houver um risco sistêmico cria o problema do moral hazard, i.e., a tendência de correr riscos excessivos devido ao seguro representado pela possibilidade de redesconto. Logo, como provedor desse seguro, o $\mathrm{BCl}$ deve ter o poder de regular as operações dos bancos. A função de fiscalização, entretanto, poderia ficar a cargo de outras agências governamentais, até mesmo porque evita desgastes em caso de fraudes financeiras, dificeis de serem detectadas de qualquer modo.

A "purificação" do Banco Central vem sendo defendida, tanto no Brasil - por, entre outros, Brandão (1992) e Cysne (1993) - como em outros paises A revista The Economist (28/08/93), discutindo a necessidade de conferir maior autonomia para o Banco da Inglaterra, afirma que o relativamente fraco desempenho do Banco Central inglês deve-se, em parte, ao excessivo número de suas atribuições, que vão além de buscar a estabilidade dos preços e a estabilidade do sistema monetário e de pagamentos. No caso brasileiro, essa redefinição seria ainda mais premente, dado que o Bacen, além de regulamentar, cuida também da fiscalização dos mais variados tipos de instituições financeiras, consórcios de autómoveis, etc

\section{REGRAS MONETÁRIAS FIXAS}

\subsection{A questão teórica da regra versus politicas discricionárias}

\footnotetext{
17. Akhtar e Howe (1991) chegam a conclusões semelhantes, atribuindo isso ao fato de que o FED tem constitucionalmente outras atribuiçöes além de manter a estabilidade dos preços.
} 
As últimas décadas têm assistido a um inconclusivo debate entre uma linha de pensamento, que vagamente poderiamos chamar de "keynesiana", ou "neokeynesiana", enfrentando uma verdadeira avalanche de publicações de linha "monetarista" - sempre no sentido vago que Ihes é atribuido por Kindleberger - em torno da melhor maneira de se conduzir a política monetária. Para os monetaristas um contingente composto por monetaristas propriamente ditos (como Milton Friedman), e por uma espécie de tropa de choque da escola dos "novos" macroeconomistas (os novos-clássicos e os novos-keynesianos) ${ }^{18}$ - a melhor política monetária é não ter política monetária de curto prazo, tipo "sintonia fina", com o objetivo de administrar a demanda. Friedman (1959 e 1968) foi um dos primeiros a propor uma "constituição monetária", não para dar independência ao Banco Central, mas para fazê-lo cumprir uma dada regra de longo prazo, que poderia ser estabelecida até mesmo via uma emenda constitucional. As políticas ativistas adotadas pelos keynesianos antigos - para não confundir com os "novos"-, amparadas pelas conclusões práticas da curva de Philips, estariam na origem das flutuações econômicas. Mas Friedman aceitava que, no curto prazo, uma política ativa poderia ter influência sobre o nivel de atividade.

Os adeptos das expectativas racionais radicalizaram: uma política monetária discricionária só poderia dar resultados se os agentes fossem por ela surpreendidos, já que, agindo racionalmente, simplesmente se antecipariam às medidas anunciadas, tornando-as, portanto, inócuas. A grande vantagem de se estabelecer uma regra fixa na condução da política monetária é que reduziria sobremaneira os erros na formação das expectativas e os custos com a redução da inflação. Na medida em que as expectativas inflacionárias influenciam o próprio processo inflacionário, uma política de combate à inflação que tenha credibilidade i.e., executada por um $\mathrm{BCl}$ obedecendo a uma regra fixa - serviria com um poderoso fator de estabilização. Por outro lado, uma política monetária ativa - a chamada "sintonia fina" - é problemática porque, mesmo que a intenção das autoridades seja a melhor possivel, uma política considerada ótima hoje pode não ser considerada ótima amanhã, o que poderia levar o governo a voltar atrás em seu compromisso de seguir uma determinada política, isto é, a procurar enganar os agentes econômicos, o que provocaria um maior grau de incerteza na economia. ${ }^{19}$

As regras monetárias, como lembra Barro (1986), podem ser quantitativas (base monetária, $M 1$, etc) ou de preços (inflação, taxa de juros, etc) A regra quantitativa mais comum na literatura, e a que, no passado, foi a mais utilizada em diversos países, é a que restringe a expansão monetária a um certo percentual por período de tempo, geralmente um ano. Esse tipo de regra, muito popular no final dos anos 70 e início dos 80 , já não é mais seguida em praticamente país algum. As razões desse abandono estão na dificuldade de definir moeda e na inexistência de uma

\footnotetext{
${ }^{18}$ Para um resumo dos fundamentos teóricos dos novos clássicos, ver Barbosa (1992). O pensamento novo-keynesiano está condensado em Mankiw (1988). Ambas as escolas assumem que os agentés se comportam racionalmente, e estăo interessadas em desenvolver os fundamentos microeconômicos da macroeconomia A principal diferença entre elas está em que, enquanto os novos-clássicos se dedicam a estudar os desequilibrios do mercado de trabalho, os novos-keynesianos pesquisam os desequilíbrios dos mercados de bens e serviços

${ }^{19}$ Esse fenômeno é conhecido na literatura como "inconsistência temporal dos planos ótimos" Para um sumário atualizado sobre a questão da credibilidade e da inconsitência temporal da politica monetária ver Blackburn (1992) Ver ainda Barro (1986)
} 
relação estável entre o comportamento dos agregados monetários e variáveis como o nivel dos preços e atividade econômica. Mas a idéia persiste em certos meios acadêmicos, principalmente na versão "friedmaniana", segundo a qual essa meta de expansão monetária deveria ser simplesmente fixada para sempre, o que colocaria o Banco Central em uma espécie de "piloto-automático".

Desde meados dos anos 80 , diversos bancos centrais desviaram suas atenções para variáveis-preço, mais exatamente a taxa de juros e a de câmbio. Isso não quer dizer, contudo, que o controle do estoque de moeda tenha sido desprezado pelos economistas. Tem surgido um grande número de propostas de regras monetárias que levam em consideração as dificuldades da regra simples defendida por Friedman. O novo-clássico Barro (1986), por exemplo, discorda do uso de metas quantitativas de expansão monetária porque a velocidade da moeda oscila com as variações nas taxas de juros. Além disso, ele alerta para o fato de que a demanda por moeda pode aumentar após a estabilização, frustrando a meta de expansão de moeda predeterminada e fazendo a política monetária perder credibilidade. Barro defende uma regra mista, ao mesmo tempo quantitativa e de preço: a oferta de moeda (no caso, a base monetária) cresceria (ou diminuiria) a um ritmo predeterminado, de acordo com o comportamento da taxa de inflação Em outras palavras, a meta a ser atingida não seria a oferta de moeda, mas sim a inflação, mas com um feedback. se a taxa de inflação superasse a meta durante certo tempo, a base monetária passaria a crescer mais lentamente, e vice-versa. Isso permitiria maior flexibilidade, sem perda de credibilidade.

Essas visões teóricas têm dado sustenção às mais diferentes políticas monetárias, com grandes modificações sendo introduzidas no cenário internacional, principalmente desde o início dos anos 70 (Goodhart, 1989) No Brasil, a posição de nossas autoridades monetárias tem sido, desde sempre, simplesmente pragmática. A sintonia fina tem sido aplicada na prática e sofrido mudanças mais ou menos abruptas, com quebras nas regras do jogo sendo uma constante. Não obstante, uma atitude tem se mantido constante: o estabelecimento de metas monetárias, geralmente para o período de um ano Como sói acontecer, essas metas não são atingidas nunca. De qualquer maneira, metas de expansão monetária perderam completamente o sentido, uma vez que o estoque de meios de pagamento tem crescido a um ritmo inferior ao da inflação desde o final da década de 70 , o que seria de esperar com o aumento sistemático do nivel de preços. Assim, dentro do atual quadro inflacionário brasileiro, não faz sentido propor aperto monetário, porque estatisticamente ele já existe.

\subsection{Metas monetárias e os limites do controle de expansão da moeda}

Entretanto uma questão mais de fundo, anterior a essas, é saber se é possivel controlar o estoque de moeda. Dito de outra forma, antes de procurar discutir os possiveis impactos sobre a economia de uma dada expansão do estoque de moeda, é preciso verificar se um $\mathrm{BC}$, mesmo que independente, tem o poder de determinar a taxa de expansão monetária. A evidência empírica tem mostrado que não. No Brasil, mesmo na década de 70 , quando os instrumentos de política monetária já haviam se desenvolvido e a economia não sofria as distorçôes conhecidas na 
década de 80 , as metas monetárias foram sistematicamente subestimadas. ${ }^{20} \mathrm{Da}$ mesma forma, um $\mathrm{BCl}$ como o Bundesbank não tem mostrado capacidade de conter a expansão monetária dentro de sua programação. Os Estados Unidos e o Japão, por sua vez, vivem um problema semelhante, mas com sinal inverso apesar de seus bancos centrais estarem fomentando um aumento do crédito para ajudar na recuperação de suas economias, tendo para isso reduzido as respectivas taxas de juros de curto prazo para niveis não verificados das últimas três décadas, a resposta do setor privado tem sido muito aquém do esperado. Estabelecer metas que não poderiam ser cumpridas não parece ser a melhor maneira de se conceder credibilidade à política monetária, com ou sem um $\mathrm{BCl}$.

A dificuldade de controlar o estoque de moeda deve-se, fundamentalmente, a dois fatores' à endogeneidade da moeda e à dificuldade de mensurar o saldo dos meios de pagamento. A questão da endogeneidade da moeda significa que a moeda é criada a partir das decisões dos agentes econômicos, e não através de uma decisão das autoridades monetárias. Um dos primeiros autores deste século a chamar a atenção para esse fato foi Kaldor $(1970$; 1982) Ao entender a criação da moeda como fruto de uma operação de crédito, Kaldor mostra que a política monetária teria, na melhor das hipóteses, o poder de um barbante: pode segurar com muito esforço - a oferta de moeda, mas não pode empurrar moeda quando não há demanda. Outros autores na tradição pós-keynesiana têm igualmente defendido, com variações, a tese da endogeneidade da moeda (Moore, 1986 e 1988; Minsky, 1982; Davidson, 1978, Wray 1992) Moore (1988), por exemplo, afirma que um Banco Central pode controlar o preço do dinheiro, mas a quantidade será determinada pelas forças de mercado àquela taxa de juros. Mesmo assumindo uma posição menos "horizontalista", é difícil não concordar com a tese de que o Banco Central, ainda que independente, não é capaz de exercer um controle rigoroso da base monetária, e menos ainda dos outros agregados, podendo apenas, quando muito, exercer alguma influência sobre o comportamento dos agentes. E se a tese de endogeneidade da moeda é correta, mesmo parcial, estabelecer metas de expansão monetária é um exercicio, no mínimo, inútil.

Outra dificuldade na fixação de metas monetárias está na própria definição de moeda. Qual a variável a ser escolhida como meta intermediária da política monetária? O ideal seria aquela cujas variações possuissem forte correlação com as variações no PIB nominal. Entretanto, principalmente a partir do início dos anos 70 , nenhuma das variáveis - base monetária, M1, M2, etc- tem mantido uma correlação estreita com as variações no nível de preços. Com as inovações financeiras, o avanço tecnológico, a internacionalização dos mercados financeiros, etc., foram criados um sem número de instrumentos de débito e crédito que ajudam a movimentar a economia atuando no lugar da moeda tradicional, i.e., do papelmoeda e dos depósitos bancários. Com isso, a velocidade de circulação dessa moeda tradicional passou a comportar-se de maneira imprevisivel, e tornando cada vez mais irrelevante o controle do saldo dos agregados monetários como meta de política monetária. $^{21}$

\footnotetext{
${ }^{20}$ Havia o problema da conta-movimento, que certamente invalidava, ao menos em parte, os esforços do Banco Central, que nada tinha de independente.

${ }_{21}$ Hayek (1978, p 49) resume essa discussão da seguinte forma: "Sempre considerei ütil explicar a meus alunos que é pena qualificarmos o dinheiro como substantivo, e que seria mais útil para a compreensão
} 


\section{CONSIDERAÇÕES FINAIS}

\subsection{As âncoras em resumo}

A âncora cambial, i.e., a fixação da taxa de câmbio, é uma regra muito difícil de ser mantida, como mostra fartamente a experiência internacional. Os riscos de se verificar uma rápida sobrevalorização cambial são evidentes em uma economia onde a participação do comércio exterior na renda nacional ainda é muito pequena e a memória inflacionária muito recente. A defasagem do câmbio teria efeitos recessivos, inutilmente. Por sua vez, a dolarização (ou âncora nominal), em que a fixação do câmbio adiciona-se à conversibilidade de toda a moeda em circulação, apresenta a dificuldade adicional de vincular o estoque de moeda às reservas internacionais: se as reservas diminuem, a conversibilidade poderá ser posta em questão, a não ser que se acredite na tese de ajuste automático, tese essa que, apesar de defendida há mais de dois séculos, ainda está por ser comprovada.

Se a fixação da taxa de câmbio é uma regra, como muitas outras, que visa colocar os gastos do governo em uma "camisa-de-força", além de buscar influir na formação das expectativas inflacionárias, o estabelecimento de regras fixas de expansão monetária tenta igualmente cumprir essas funções, mas difere das âncoras externas pelo fato de conferir soberania à condução da política monetária. Esse tipo de âncora, entretanto, apresenta duas importantes dificuldades: a primeira diz respeito ao fato de que o controle sobre o estoque de moeda tem-se mostrado, na prática, inexeqüível, dado o caráter eminentemente endógeno da emissão monetária; e, em segundo lugar, porque, mesmo se, por mera coincidência, a meta monetária fosse alcançada, não estaria garantido que atingisse seus objetivos quanto à estabilização, já que não há uma relação direta entre moeda e preços.

\subsection{BCl: uma proposta politicamente correta?}

Levando em consideração a advertência de Stein (1988) - segundo o qual o problema da política econômica é que algo precisa ser feito, mesmo quando não sabemos exatamente o que fazer - discutimos a seguir a proposta de criação de um Banco Central independente até certo ponto, e a partir do cumprimento de alguns pré-requisitos. De inicio, é preciso esclarecer que, por Banco Central independente, entenda-se uma autoridade monetária cujas contas estejam inteiramente separadas das do Tesouro Nacional e cujas ações estariam imunes a pressões políticas conjunturais. Nessa "constituição monetária", o Banco Central teria como função básica perseguir o objetivo de obter a estabilidade dos preços e, ao mesmo tempo, em parte, contraditoriamente, de manter a estabilidade do sistema bancário e de pagamentos. A fiscalização do sistema financeiro e a administração de um eventual seguro de depósito bancário poderiam ficar a cargo de alguma outra instituição vinculada ao Ministério da Economia, mas sempre em sintonia com o Banco Central. Essa "purificação" das funções do Bacen possivelmente diminuiria as resistências à criação de um BCl (Cysne, 1993)

A política monetária específica a ser seguida não obedeceria necessariamente nem preferencialmente - nenhuma regra em particular, e a decisão sobre essa política específica seria tomada por algum tipo de Comitê Monetário, onde

dos fenômenos monetários se "dinheiro" fosse um adjetivo descrevendo uma propriedade que diferentes objetos poderiam possuir, em graus variados." 
estivessem representados diversos segmentos da sociedade. Uma vez estabelecida, essa política seria seguida pelo Banco Central sem ingerências externas. $O$ presidente do Banco teria mandato fixo e teria de prestar contas de suas ações ao Congresso. A única exigência é que não deveria ser permitido o financiamento direto do governo, sendo o financiamento indireto - que se dá através das operações de mercado aberto - limitado por lei, a não ser em casos limites de guerras, grandes catástrofes etc. A grande vantagem dessa proposta sobre a que fixa regras (cambiais ou monetárias) é que daria flexibilidade, i.e., margem de manobra, à âncora, sem que no entanto esta perdesse credibilidade

Nunca é demais lembrar, entretanto, que se a simples concessão de autonomia para o Bacen pudesse trazer estabilidade, alguém já teria feito isso antes. Mas, como também lembrou Eugênio Gudin, não é qualquer país que pode ter um Banco Central independente. A plena autonomia do Bacen depende do preenchimento de determinados requisitos, acima de todos um certo equilibrio orçamentário. $\mathbf{E}$ evidente que isso não quer dizer necessariamente que o governo não possa gastar mais do que arrecada, mas que não pode ser visto como um eterno deficitário, sob pena de fazer o Bacen perder credibilidade no combate à inflação. A questão fundamental é a divida pública, ou seja, a capacidade do governo federal de administrá-la sem que a taxa de juros se eleve demasiadamente. Não se deve, como se faz hoje em dia, deixar esse encargo apenas com o Banco Central, já que este acaba sendo obrigado a acomodar as pressões advindas das necessidades de financiamento do setor público, incluindo, indiretamente, dos estados (e seus bancos) e dos municípios.

A concessão de autonomia plena para o Banco Central representaria, portanto, como no caso dos outros tipos de âncora, a imposição de uma "camisa-de-força", e essa constitui-se, aliás, na principal razão de não ter acontecido até hoje. Nesse aspecto, existe, entretanto, uma diferença importante em relação às outras âncoras: as âncoras externas são geralmente vistas como uma solução, acima de tudo, de curto prazo - e dai a tentação sempre presente de lançá-las - e que, portanto, se não derem certo o governo pode a qualquer momento rever sua posição; por outro lado, um Banco Central teria de ter sua independência referendada pela Constituição e esta, como se sabe, não é fácil de ser revista.

Para finalizar, recordemos que credibilidade é fundamental para qualquer plano de estabilização, e que esta credibilidade está vinculada ao entendimento, por parte da sociedade, de que o plano será levado adiante por um periodo suficientemente longo para apagar a memória inflacionária e para que se possam realizar as reformas estruturais desejadas. Essa perspectiva de longo prazo, por sua vez, depende basicamente de dois fatores. Em primeiro lugar, depende de que o plano, analisado em seus aspectos econômicos, seja considerado factivel, o que inclui ter flexibilidade suficiente para contornar choques externos. Não estabelecer metas, nem cambiais nem monetárias, pode não resolver esse problema, mas certamente ajuda a combater incertezas e movimentos especulativos contra o plano. $E$, em segundo lugar, mas não menos importante, é preciso que a sociedade acredite que o plano terá apoio político-partidário prolongado. Esse apoio, idealmente, deveria surgir de um movimento que envolvesse o maior número possivel dos segmentos representados no Congresso Nacional, em torno da aprovação de um projeto econômico e social para o País. Essa talvez seja a questão política mais delicada, 
na medida em que teria forçosamente de incluir um firme compromisso, por parte daqueles que mais têm se beneficiado da inflação, de aceitar uma divisão de perdas que seja suficiente para a obtenção, e posterior manutenção, da estabilidade dos preços.

\section{BIBLIOGRAFIA}

AKTAR, MA. e HOWARD, Howe The political and institutional independence of U.S. monetary policy Banca Nazionale del Lavoro. Quarterly Review n. 178, set 1991.

ARCELLI, Mario // ruolo della Banca Centrale nella politica economica II Mulino, 1992

BAPTISTA Jr. Paulo N Dolarizaçāo, âncora cambial e Resenvas Internacionais. Revista de Economia Politica, v. 13, n. 3, jul /set 1993

BARBOSA, Eraldo $S$ Uma exposiçăo introdutória na macroeconomia novo-clássica in. Silva, Maria L.F Moeda e Produção: Teorias Comparadas Brasilia: Editora UnB, 1992

BARRO, R J Recent developments in the theory of rules versus discretion. Economic Journal, v. 96, 1986

BELLUZZO, Luiz G; ALMEIDA, Julio Sergio G de A queståo da dolarização. In Belluzzo e Baptista Jr Paulo N.(orgs.) A Luta pela Sobrevivência da Moeda Nacional. Paz e Terra, 1992.

BLACKBURN, Keith. Credibility and time-consistency in monetary policy in. Dowd e Lewis, 1992

BRANDÄO, Carlos Reforma do sistema financeiro nacional. Trabalho apresentado no Seminário de Reforma do Sistema Financeiro. EPGE/FGV e Fipe/USP, 1992.

BRUNI, Franco. Sui rapporti fra politica monetaria, regolamentazione financiaria e vigilanza. Giornale Degli Economisti e Annali di Economia, vol. LI (N S), n. 1-4, jan -abr 1992

e Mario Monti Autonomia della banca centrale, inflazione e disavanzo publico ossevarzioni sulla teoria e sul caso italiano. In Arcelli, 1992

BURDEKIN, Richard, LANEY, Leroy $O$. Fiscal policymaking and the central bank institutional constraint Kyklos, v 41, fasc 4,1988

CARVALHO, Carlos E Âncora cambial, conversibilidade e dolarização. In. BELLUZZO e BAPTISTA Jr (orgs.) A Luta pela Sobrevivência da Moeda Nacional Paz e Terra, 1992.

CORDEN, W Max Exchange rate policies for developing countries, Economic Journal, $n .103$, jan 1993.

CYSNE, Rubens Reforma financeira - aspectos gerais e análise do projeto de lei complementar. Revista de Economia Politica, v 13, n. 3 (51), jul /set 1993

DAVIDSON, Paul Money in the Real World New York. McMillan, 1978

DORNBUSCH, Rudiger; HELMERS F Leslie CH The Open Economy Tools for Policymakers in Developing Countries. Oxford U.P, 1989

DORNBUSCH, Rudiger, FISHER, Stanley Macroeconomia. $5^{\circ}$ ed, Makron Books, 1991

DOWD, Kevin, LEWIS, Mervynk K Current Issues in Financial and Monetary Economics Macmillan, 1992

EIJFFINGER, Sylvester; SCALDING, Erìc Central bank independence in twelve industrial countries Banca Nazionale del Lavoro Quarterly Review,n 184, mar 1993

FRANCO, Gustavo Gradualismo e Dolarização Revista de Economia Politica, v 13, n.2, abr -jun. 1993

FRIEDMAN, Milton. Capitalism and Freedom. Chicago. The University of Chicago Press, 1962. The role of monetary policy. American Economic Review, v. 18, n. 1, mar 1968.

1983 Bright Promises, Dismal performance. An Economist's Protest Harcourt Brace Jovanovich,

GOODHART, Charles. The Evolution of Central Banks. MIT Press, 1988

The conduct of monetary policy. Economic Journal, n 99, jun. 1989

Alternative monetary standards In. Dowd e Lewis, 1992

GUDIN, Eugenio Princípios de Economia Monetária v.1, ed 8, Livraria Agir Editora, 1972

HAAN, Jakob de, STURM, Jan E. The case for central bank independence. Banca Nazionale del Lavoro Quarterly Review, n.182, setembro 1992

HAYEK, Frederich A Desestatização do Dinheiro Instituto Liberal, 1978.

HOLTHAM, Gerald No case for independent central bank. Financial Times, 03/09/1993

KALDOR, Nicholas. The new monetarism. Lloyds Bank Review, julho 1970

The Scourge of Monetarism Oxford U P. 1982

KANE, Edward $\mathrm{J}$. Politics and FED policymaking. The more things change, the more they remain the same Journal of Monetary Economics, 6, 1980.

KINDLEBERGER, Charles. Manias, Panics, and Crashes Basic Books, 1978

LAIDLER, David. Monetarist Perspectives Philip Allen, 1982

LOMBARDINI, Siro Prefazione In Arcelli, 1992

LONG, J Bradford, SUMMERS, Lawrence H Macroeconomic policy and long-run growth in: Policies for Long-Run Economic Growth, Federal Reserve Bank of Kansas City, 1992 
MANKIW, N Gregory. Recent developments in macroeconomics: a very quick refresh course. Journal of Money, Credit, and Banking, v. 20, n. 3, Aug. 1988, part 2.

MINSKY, Hyman. Can "It" Happen Again?. M.E. Sharpe, 1982

MOORE, Basil J. How credit drives the money supply. The significance of institutional developments Journal of Economic issues, v. XX, n 2, jun. 1986

The endogenous money supply. Journal of Post-Keynesian Studies, v.X, n.3, primavera 1988

NEUHAUS, Paulo História Monetária do Brasil 1900-45. IBMEC, RJ, 1975

SAMUELSON, Paul Economics. Tenth Edition McGraw-Hill, 1976

SERRA, José. A lei do sistema financeiro: uma proposta Conjuntura Econômica, dez 1991

SIMONSEN, Mário $H$ Por que se especula que há um choque à vista? Exame, 01/09/1993

STEIN, Herbert Comment Journal of Money, Credit, and Banking, v 20 n. 3, Aug 1988, part 2

VÉGH, Carlos A. Stopping high inflation. IMF Staff Papers, v 39, set 1992.

WILLIAMSON, John. Exchange reserves as shock absorbers In: Dornbusch e Helmers, 1989.

WRAY, L Randall Commercial banks, the central bank, and endogenous money. Journal of post Keynesian Economics, , v. 14, n. 3, primavera 1992.

\section{ABSTRACT \\ MONETARY ALTERNATIVE STANDARDS: CONSIDERATIONS ABOUT THE BRAZILIAN CASE}

This article analyses the main characteristics, the difficulties and the inherent risks of cambial and monetary anchors in Brazil. First of all, it discusses two cases of cambial anchor (a) the fixation of the exchange rate and $(b)$ the nominal anchor - it means the situation in which there is convertibility. Second, the discussion about monetary anchors are related to hypoteses of (a) independence of Central Bank and (b) rules concerning about monetary expansion 